\title{
High Prevalence of Diffuse Parenchymal Lung Diseases among Turkish Tinners
}

\author{
Oner Dikensoy ${ }^{1}$, Resat Kervancioglu ${ }^{2}$, İbrahim EgE ${ }^{1}$, Nevin Uysal ${ }^{1}$, Osman ElbeK ${ }^{1}$ and \\ Ayhan OzKuR ${ }^{2}$
}

${ }^{1}$ Department of Pulmonary Diseases and ${ }^{2}$ Department of Radiology, Gaziantep University, Turkey

\begin{abstract}
High Prevalence of Diffuse Parenchymal Lung Diseases among Turkish Tinners: Oner Dikensoy, et al. Department of Pulmonary Diseases, Gaziantep University, Turkey-The objective is to investigate the prevalence of parenchymal lung diseases among tinners. Twenty-four tinners who signed an informed consent form in the Gaziantep area were the subjects of this study. Demographics, spirometric test results, and high resolution computed tomography (HRCT) scans were obtained for all the tinners. Out of 24 tinners, eleven tinners (46\%) had HRCTs consistent with DPLD. Of these 11 subjects, HRCT findings were consistent with respiratory bronchiolitis interstitial lung disease in nine, usual interstitial pneumonia pattern in one, and non-specific interstitial pneumonia in one. HRCT patterns consistent with DPLDs are significantly prevalent among Turkish tinners. This is the first field study reporting this occupational lung hazard in tinners. Future research is needed to uncover the underlying mechanisms. (J Occup Health 2008; 50: 208-211)
\end{abstract}

Key words: Tin, Tinners, Lung, High resolution computed tomography

Tinning is an ancient occupation, which has been practiced for centuries in the Anatolian region. More than a few decades ago, copper was the most commonly used material in the production of kitchen appliances in Turkey. When the Turks bought copper goods from a copper shop, often the place of production, they would deliver the copper goods to a shop that was specialized in tinning ("kalayci"). Nowadays, the numbers of the tinners are decreasing significantly due to fact that copper has lost it's popularity to steel and aluminum which are currently the most common metals used in the production

Received Jul 24, 2007; Accepted Nov 30, 2007

Correspondence to: O. Dikensoy, Department of Pulmonary Diseases, Gaziantep University, 27310 Gaziantep, Turkey

(e-mail:dikensoy@yahoo.com) of kitchen appliances.

Tin oxide is a mild irritant and has been reported to cause insignificant pulmonary effects in humans ${ }^{1)}$. Exposure to tin oxide has resulted in mild irritation to the eyes, skin and mucous membranes (concentration and duration not specified) ${ }^{1}$. Chronic exposure to tin oxide may result in the development of stannosis, a benign pneumoconiosis ${ }^{1)}$. To the best of our knowledge, no previous study has reported a high prevalence of diffuse parenchymal lung disease (DPLD) among workers who are exposed to tin or its side products, such as tin oxide. In this study, we aimed to screen all the tinners in the Gaziantep region to investigate the prevalence of lung pathologies which may be related to exposures during the tinning process.

\section{Materials and Method}

\section{Subjects}

This study was carried out between June 2002 and March 2003 at the Department of Pulmonary Diseases of Gaziantep University Hospital. All the participants signed an informed consent form. The study protocol was approved by the local institutional ethics committee.

All the tinners in Gaziantep city center and a nearby town (Nizip) were visited personally and invited to participate in the study.

\section{Physical examination and questionnaire}

Physical examinations were performed by a pulmonary resident (IE). A standard questionnaire including questions related to demographics and the details of occupational and environmental exposure was administered to all tinners ${ }^{2}$.

Radiological evaluation and definitions of diffuse parenchymal lung diseases

Conventional chest $\mathrm{X}$-rays and high resolution computed tomographies (HRCT) were obtained for all the subjects. HRCT of the lungs was obtained at three 
levels: upper lung field, at the vicinity of the aortic arch; middle lung field, at the vicinity of the tracheal bifurcation; and lower lung field, $1-3 \mathrm{~cm}$ above the right hemidiaphragm.

Radiological evaluation was performed separately by two different radiologists (RK and AO). The radiologists did not have any information about the clinical conditions of the subjects prior to the radiological examinations.

HRCT findings were accepted to be consistent with a respiratory bronchiolitis interstitial lung disease (RBILD) pattern when HRCT findings include a patchy limited ground-glass attenuation, poorly defined centrilobular micronodules, bronchial wall thickenings, and areas of regional hypo-attenuation. HRCT findings were accepted to be consistent with a non-specific interstitial pneumonia (NSIP) pattern if ground-glass attenuation was associated with lobar volume loss, reticulation, and/or traction bronchiectasis predominantly in the subpleural and/or peribronchovascular and basilar regions. Finally, HRCT findings were accepted to be consistent with a usual interstitial pneumonia (UIP) pattern if a bilateral, predominantly basal and subpleural, reticular pattern with subpleural cysts (honeycombing) and/or traction bronchiectasis existed, and there was minimal or no ground-glass attenuation.

\section{Spirometric measurements}

Spirometric measurements were performed by a trained spirometry technician with an automated spirometry device (2400 Pulmonary Function Laboratory, Sensormedics, Netherlands). All the measurements and the analysis of the spirometric data were performed according to American Thoracic Society standards ${ }^{3)}$. Forced expiratory vital capacity (FVC), Forced Expiratory Volume in the first second (FEV1), peak expiratory flow (PEF), and expiratory mid flows (FEF 25-75) were recorded during the spirometric measurements.

\section{Other laboratory tests}

Arterial blood gas analyses and echocardiographies were performed for all subjects. Whole blood cell counts, kidney and liver function tests (urea, creatinin, serum alanine amino- transferase, aspartate amino transferase) and serological tests (Anti-Streptolysin O, C-reactive protein, rheumatoid factor, anti-nuclear antibody, dsDNA, LE, AntiHCV) were performed only for those who had radiological evidence of diffuse parenchymal lung diseases.

\section{Tinning process}

First, a copper piece is dipped into a sulfuric acid bath. This removes the dirt and grime but endangers the copper in no way. The acid is rinsed off with water. Then the item is briskly plunged several times into a container of wet sand. The sand etches small scratches into the



Fig. 1. Tinner exposed to vapor during the process of tinning.

copper's surface, allowing the tin to adhere more readily when applied. Next, the copper is heated to a high temperature over an open flame. This flame is fed by butane gas. While the copper object is hot, ammonium chloride powder is sprinkled on the surface. The ammonia also prepares the copper surface for the application of tin. The tin itself is then applied, either by rubbing a bar of tin directly on the heated copper or by sprinkling small balls of granulated tin on the hot metal (Fig. 1). The tin, now liquefied, is spread evenly over the surface with a ball of cotton, held by hand or attached to a stick. Two coats are recommended for maximum protection.

\section{Statistical analysis}

Statistical analyses were performed with Sigma Stat 3.5 computer software. All data are presented as the mean with the range of the numerical values in brackets.

\section{Results}

Thirty tinners who are currently working in Gaziantep city centre and a nearby town (Nizip) were found. Twenty-four of these 30 tinners agreed to participate in the study.

All the subjects were male with a mean age of 54 (range, 34-77). The mean duration of working was 41.4 (range, 18-68) yr. Eighteen of the workers (75\%) were smokers. Sixteen of the subjects $(66.6 \%)$ had a history of living in a village house whitewashed with white soil that had the potential to containing asbestos. All the subjects were residents in modern buildings during the study period with no risk of asbestos exposure. Therefore, 
sampling the material from whitewash or soil for further analysis was not possible. None of the subjects had a history of long time exposure to biomass or any kind of animal.

Only three of the subjects had co-morbidities, respectively, chronic bronchitis, chronic obstructive pulmonary disease and congestive heart failure.

The respiratory questionnaire revealed that 13 subjects (54\%) had chronic cough and dyspnea, 9 subjects (37.5\%) had wheezing, and 12 subjects $(50 \%)$ had chronic sputum history. None of the subjects declared acute respiratory symptoms occurred during tinning and no case had a previous diagnosis of stannosis.

Physical examinations revealed that 8 subjects (33\%) had bilateral fine crackles on the lung bases, 6 subjects (25\%) had expiratory ronchi, 7 subjects $(29 \%)$ had congestion on their neck veins, one subject had clubbing, and one subject had pretibial edema.

For three of the subjects, despite repeated trials of up to eight, we were unable to obtain acceptable spirometry data. Carbonmonoxyte diffusion capacity (DLCO) was measured only in five subjects due to a technical problem which we were not able to solve during the study period. Lung function tests showed that four subjects had obstructive, and 2 subjects had mixed lung function abnormality. DLCO was lower than normal in all five subjects who underwent the DLCO test. Arterial blood gas (ABG) analysis showed that 6 subjects $(25 \%)$ had mild to moderate hypoxemia $(\mathrm{PaO} 2<80 \mathrm{mmHg}$, room air), one subject had type 1 respiratory failure ( $\mathrm{PaO} 2<60 \mathrm{mmHg}$, room air), and three subjects had type 2 respiratory failure ( $\mathrm{PaCO} 2>45 \mathrm{mmHg})$. Ecocardiographic examination showed that 5 subjects (21\%) had findings related to chronic pulmonary hypertension (PAP>30 $\mathrm{mmHg}$ ).

Of the 24 tinners, 11 (46\%) had HRCT findings consistent with DPLD while the remaining 13 had normal HRCT findings. HRCT findings were consistent with RBILD pattern in $9(9 / 11,81 \%)$ patients. One patient $(1 / 11,9 \%)$ had HRCT findings consistent with UIP, whereas another $(1 / 11,9 \%)$ had HRCT findings consistent with NSIP. None of the subjects had pleural calcifications in their radiological findings.

Histopathological confirmation was undertaken only in two cases by open lung biopsy: one case with UIP, and 1 case with NSIP.

Laboratory analysis of the serum samples in patients with HRCT findings consistent with DPLD showed that liver and kidney function tests were normal for all subjects. However, one subject had a hematocrite level consistent with policytemia, and serological analysis showed that four patients had elevated C-reactive protein while two and one patient had elevated rheumatoid factor and antinuclear antibody levels, respectively. Anti-HCV was negative in all subjects.

\section{Discussion}

The results of this study show for the first time that the prevalence of DPLD among tinners in the Gaziantep area is remarkably high (46\%). The most prevalent HRCT pattern was RBILD, followed by UIP and NSIP.

Tinners are exposed mainly to three different substances: tin oxide, ammonium chloride and sulfuric acid. The copper material is first dipped into a sulfuric acid bath at room temperature. This is a short procedure which takes about one minute and we did not notice any irritating smell or vaporous reaction during this process. Also, we could not find any data in the medical literature suggesting that exposure to sulfuric acid causes any pulmonary side effects or complication. After dipping into the sulfuric acid bath, ammonium chloride powder is sprinkled on the preheated surface of the copper article to prepare the surface for the application of tin. The tin itself is then applied by rubbing a bar of tin directly on the heated copper. This procedure causes a vaporous smoke that is inhaled by tinners for at least five minutes (Fig. 1). Previous data suggest that exposure to tin oxide causes a benign pathology, so-called "stannosis". It is a simple pneumoconiosis and is diagnosed by nodular opacities found in chest X-ray ${ }^{4}$. It usually does not cause any symptoms ${ }^{4}$. None of the subjects in the present study had a recent or previous history or clinical or radiological findings consistent with stannosis. Ammonium chloride is a water soluble substance ${ }^{2)}$. Therefore, its deep inhalation to the lower airways is not easily possible, unless an acute and massive exposure occurs ${ }^{2}$. In such conditions acute lung injury may occur ${ }^{2}$. It appears that the chronic exposure to ammonium chloride experienced by the tinners is not responsible for the HRCT abnormalities found in this study. We could not find any data on the pulmonary side effects of a such mixture of tin and ammonium chloride. We suggest that the fume occuring due to mixture of these compounds on the hot metallic surface might be responsible for the abnormalities found on the HRCT scans of the tin workers.

Since none of the subjects had pleural calcifications we exclude the possibility of asbestosis. We suggest that silicosis was also unlikely, because during the procedure when workers use sand to make scratches on the surface of the copper article it was not possible to inhale wet sand particles. We also investigated whether the tin bars contained any other metals such as lead or cadmium by telephoning the manufacturers. They claimed that the tin bars are solely made of tin. Therefore we excluded the possibility of long term cadmium and lead exposure.

RBILD was the most prevalent HRCT pattern seen in the present study. It was found in $37 \%$ (9/24) of all the tinners and $81 \%$ (9/11) of those who had HRCT patterns consistent with DPLD. RBILD is generally defined as a 
condition characterized by substantial pulmonary symptoms, abnormal pulmonary function, and imaging abnormalities ${ }^{5)}$. HRCT findings of RBILD include extensive ground-glass opacity, and centrilobular nodules $^{6-8)}$. The CT features of RBILD may be similar to those of hypersensitivity pneumonitis (HP) and NSIP ${ }^{6}$. $\mathrm{HP}$ is the result of an immunologically induced inflammation of the lung parenchyma in response to inhalation exposure to a large variety of antigens ${ }^{9}$. HP tends to occur in non-smokers and profuse poorly defined nodules of ground-glass attenuation in HRCT scans are very suggestive of $\mathrm{HP}^{10)}$. RBILD usually affects heavy smokers with an average exposure of more than 30 packyears ${ }^{11)}$. The clinical differentiation of RBILD from hypersensitivity pneumonitis is facilitated by exposure history and by the fact that most patients with hypersensitivity pneumonitis are non-smokers ${ }^{10,11)}$. In the present study, RBILD was considered to be present on the basis of the HRCT findings and associated findings such as effort dyspnea and fine crackles on the lung bases. Although, we are not aware of any data suggesting that exposure to a mixture of tin and ammonium chloride causes hypersensitivity pneumonia, we can't rule out the possibility of this condition in the tin workers.

In conclusion, the results of this study show that the prevalence of HRCT abnormalities compatible with DPLD among Turkish tinners is significantly high. This is a field study reporting for the first time that tinning may cause an occupational pulmonary hazard. We suggest that future research is needed to understand the underlying mechanisms of this hazardous effect.

\section{References}

1) U.S. Department of Labor, Occupational safety and health guideline for tin oxide, 1996. (online), available from <http://www.osha.gov/SLTC/healthguidelines/ tinoxide/recognition.html>, (accessed 2008-02-26).

2) Ferris BG: Epidemiology Standardization Project
(American Thoracic Society). Am Rev Dis 118, 1-20 (1978).

3) Miller MR, Crapo R, Hankinson J, Brusasco V, Burgos F, Casaburi R, Coates A, Enright P, van der Grinten CP, Gustafsson P, Jensen R, Johnson DC, MacIntyre N, McKay R, Navajas D, Pedersen OF, Pellegrino R, Viegi $G$ and Wanger J; ATS/ERS Task Force: General considerations for lung function testing. Eur Respir J 26, 153-161 (2005)

4) Sluis-Cremer GK, Thomas RG, Goldstein B and Solomon A: Stannosis. A report of 2 cases. S Afr Med J 4;75, 124-126 (1989)

5) Lynch DA, Travis WD, Muller NL, Galvin JR, Hansell DM, Grenier PA and King TE Jr: Idiopathic interstitial pneumonias: CT features. Radiology 236, 10-21 (2005)

6) Holt R, Schmidt R, Godwin J and Raghu G: High resolution $\mathrm{CT}$ in respiratory bronchiolitis-associated interstitial lung disease. J Comput Assist Tomogr 17, 46-50 (1993)

7) Turner-Warwick M: Connective tissue disorders and the lung. Aust N Z J Med 16, 257 (1986)

8) Gruden JF and Webb WR: CT findings in a proved case of respiratory bronchiolitis. AJR Am J Roentgenol 161, 44 (1993)

9) Fink JN, Ortega HG, Reynolds HY, Cormier YF, Fan LL, Franks TJ, Kreiss K, Kunkel S, Lynch D, Quirce S, Rose C, Schleimer RP, Schuyler MR, Selman M, Trout D and Yoshizawa Y: Needs and opportunities for research in hypersensitivity pneumonitis. Am J Respir Crit Care Med 171, 792-798 (2005)

10) Lynch DA, Rose CS, Way D and King TJ: Hypersensitivity pneumonitis: sensitivity of highresolution CT in a population-based study. Am J Roentgenol 159, 469-472 (1992)

11) Heyneman LE, Ward S, Lynch DA, Remy-Jardin M, Johkoh T and Muller NL: Respiratory bronchiolitis, respiratory bronchiolitis-associated interstitial lung disease, and desquamative interstitial pneumonia: different entities or part of the spectrum of the same disease process? AJR Am J Roentgenol 173, 16171622 (1999) 